Original article

\title{
HISTOLOGICAL CHARACTERISTICS OF FOLLICULOGENESIS IN MURRAH WATER BUFFALOES DURING THE EARLY POSTPUBERTAL PERIOD
}

\author{
V. MANOV, V. PLANSKI \& G. S. POPOV \\ Faculty of Veterinary Medicine, University of Forestry, Sofia, Bulgaria
}

\section{Summary}

Manov, V., V. Planski \& G. S. Popov, 2020. Histological characteristics of folliculogenesis in Murrah water buffaloes during the early postpubertal period. Bulg. J. Vet. Med., 23, No $1,80-88$.

A characteristic feature of water buffalo heifers is that they approach breeding maturity later than bovine heifers. From a physiological and endocrinological view, this is related to a later puberty, which affects the overall reproductive performance of water buffalo. The aim of this study was to highlight some morphological characteristics of the water buffalo (Bubalus bubalis) ovaries in the early postpubertal period. The results showed active ovaries of the examined specimens. Some of the follicles had no oocyte, but were with normal structure and physiological activity. Histology is a definitive method for examination of ovarian activity in water buffaloes. In some of the ovulating follicles the oocyte was absent during early puberty. The presence of corpora lutea confirmed the endocrine maturity of the hypothalamus-pituitary-gonadal endocrine axis in 11-14 months old heifers despite the absence of oocytes.

Key words: corpus luteum, estrus, follicle, ovary, ovulation, postpubertal period, water buffalo heifer

\section{INTRODUCTION}

Water buffalo heifers attain breeding maturity later than bovine heifers which is attributed to later onset of puberty, affecting the overall reproductive performance. In dairy cattle, reproductive performance is mainly affected by milk production (Slavkova et al., 2017), whereas live body weight gain and the season of puberty onset are more important for reproductive management in water buffaloes (Planski et al., 2017a). Water buffalo puberty age is variable and is influenced by a wide variety of factors, including climate, geographic area, breed, season of birth, and nutrition (Peeva et al., 1993).

Research papers documenting the time of onset of puberty in water buffaloes vary considerably in their findings as to age ranges at which this can be expected to occur. According to Jainudeen \& Hafez (1993), the river-type buffaloes approach puberty at $15-18$ months of age, whereas 
the swamp-type buffaloes exhibit normal estrus at 21-24 months of age. The onset of puberty in water buffalo is not currently clearly defined (Peeva et al., 1993; Borghese et al., 1996; Terzano et al., 1997; Campanile et al., 2001; Singh et al., 2010; Roy et al., 2016). Most of the findings are based on visual observations rather than scientific methods that take into account the endocrine status of the animals during this period. Using visual observation, the earliest detected estrus in Bulgarian local water buffaloes has been recorded at 21 months of age. Using radio-immunoassay (RIA) for hormone assessment in the same breed and crosses with Murrah, the first estrus has been endocrinologically confirmed at 19.9 months of age by Kanchev et al. (1989). In most of the presented studies in the literature, onset of puberty has been calculated retrospectively from the first calving date (Borghese, 2005). According to Roy et al. (2016) and Planski et al. (2017b), the use of serum levels of progesterone to calculate the onset of puberty is controversial. Campanile et al. (2001) used both RIA puberty confirmation and ultrasound scanning to confirm the morphological structure in the ovary responsible for the high progesterone levels.

Taneja et al. (1996) characterised the growth and regression of ovarian follicles in water buffalo, describing 7 full cycles in 5 adult females using ultrasound scanning once daily. Ovarian mapping was used, and a size of $14 \mathrm{~mm}$ for dominant follicles was specified. The results showed one or two follicular waves in each cycle, each wave being characterised by the presence of one dominant and multiple subordinate follicles. In the one wave cycle, the cohort of follicles starts to develop at day $1.3 \pm 0.7$ post oestrus. In the two wave model, the cohorts start at
$1.8 \pm 0.6$ and $7.8 \pm 2.0$ day respectively. The researchers noted that the dominant follicle diameter did not differ significantly between the two models, but on the day of ovulation, dominant follicles were by more than $4 \mathrm{~mm}$ greater than the subordinate follicles $(\mathrm{P} \leq 0.05)$.

Follicular growth, recruitment, regression and ovulation have been defined in 30 normally cycling Murrah water buffalo cows (Baruselli et al., 1997). One, two or three waves of follicular dynamics were found out. Structural development of the dominant follicle was longer in 2 and 3 wave models without significant difference in the diameter. The number of follicular waves and cycle duration depended on the activity of the corpus luteum.

Ovarian histology was used to define the normal reproductive cycle and changes associated with pregnancy in water buffalo (Baithalua et al., 2013). The ovaries and uteri of slaughterhouse specimens were examined. The classification of the stage of cycle or pregnancy detected was based on the maturity and development of the corpus luteum, superficial follicles and foetal size. Large luteal cells were circular in shape with central nuclei and multiple cytoplasmic lipid droplets. Small luteal cells were bundle shaped, with eccentric irregular nuclei and a small number of lipid droplets. The diameter of small luteal cells was approximately $12-23 \mu \mathrm{m}$, whereas the large cells were of significantly larger size $(25-55 \mu \mathrm{m})$. The observed size increase was related to the maturation of the corpus luteum (CL). The progesterone serum level was proportional to the number of luteal cells present, hence the high levels of serum progesterone recorded during diestrus and pregnancy. The authors concluded that during puberty, the mid diestrus CL was not fully mature and that, unlike cattle, was unable 
to supply sufficient progesterone to support pregnancy, supporting a hypothesis of luteal insufficiency.

The aim of this study was to examine the ovaries of water buffalo heifers during the early post pubertal period, using histological examination of the follicular dynamics at different stages of the ovarian cycle.

\section{MATERIALS AND METHODS}

\section{Animals and age of puberty onset}

We had access to 76 Murrah water buffalo heifers assigned for slaughtering. Examination was carried out on animals born during different seasons - once they were collected in the yard prior to slaughtering. The average age of the animals was 482 \pm 42 days. The examined 76 heifers were observed visually for signs of estrus 3 times a day. The observed signs were: standing at mounting, presence of clear mucous vaginal discharge and vulvar swelling - according to the method described by Suthar \& Dhami (2010).

\section{Histological examination of the ovaries}

Four heifers were randomly selected from those recognised in estrus. They were at the age of $11,12,14$ and 15 months respectively. To ascertain the exact age of the animals, the ear tag numbers of the heifers were checked against the Bulgarian Food Safety Agency database.

After slaughter, the ovaries of these heifers were collected and preserved in $3.7 \%$ formaldehyde. The histological examination of the collected specimens was carried out at the Institute of Experimental Morphology and Anthropology at the Bulgarian Academy of Sciences. The preparation was classical and the specimens were fixed in paraffin blocks, which were then sliced into $5 \mu \mathrm{m}$ layers. The preparations were then denatured and stained using haematoxylin/eosin. The prepared slides were then examined independently by two pathologists at the Department of Internal Diseases, Pathology and Pharmacology at the Faculty of Veterinary Medicine, University of Forestry, Sofia, Bulgaria. The pathologists were unware of the history of the animals the samples were derived from. Specimens were examined by light microscopy with different magnifications including immersion and a buildup camera. The software Euromex Bio Blue was used to prepare and save the photographs. The total number of examined slices was 48 (12 for each examined animal).

\section{RESULTS}

In all examined animals, the ovaries were active, with distinct cortical and medullary zones. In the periphery of the cortex, primordial follicles were noted between bundles of connective tissue. These follicles contained an oocyte and one layer of epithelial cells. The primary follicles are displayed on Fig. 1 and 2. They were outlined with the presence of oocyte and one layer of epithelial cells around. Their average diameter, including the external layer was about $36 \mu \mathrm{m}$.

In the deep layers of the parenchyma, secondary follicles with developed oocytes were present and surrounded by a thick protein membrane. Around this membrane, cuboid and prismatic cells with a trophic function were present ( $\mathrm{co}$ rona radiata). Most externally was the theca folliculi connective tissue membrane, which possessed epithelioid cells and small capillaries (Fig. 3). 


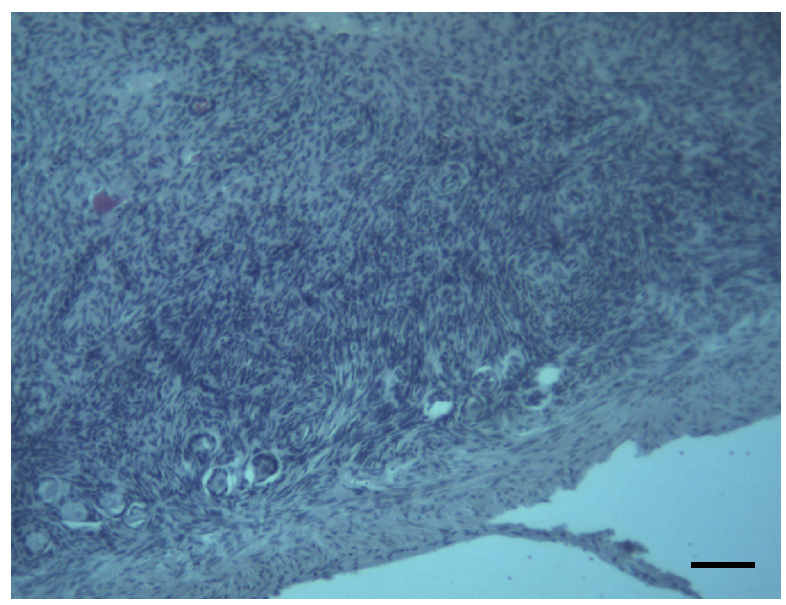

Fig. 1. Ovary from a water buffalo heifer -11 months of age: cortical zone with growing follicles in different stages. Scale bar: $153.14 \mu \mathrm{m}$.

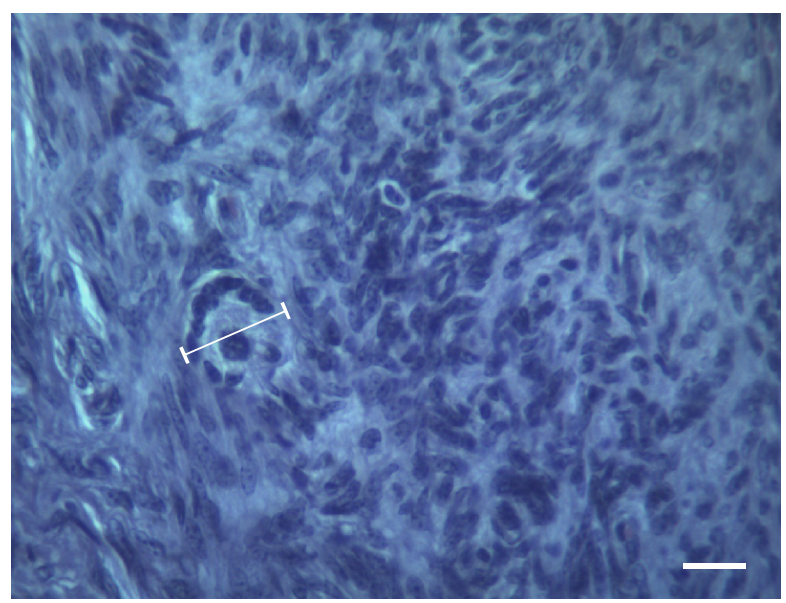

Fig. 2. Ovary from a water buffalo heifer - 12 months of age: primordial follicle (length $30.59 \mu \mathrm{m}$ ) and connective tissue cells. Scale bar: $17.30 \mu \mathrm{m}$.

Tertiary follicles were present towards the medulla of the ovarian parenchyma in 14- and 15 month-old animals. These follicles had well developed follicular fluid cavities and were surrounded with follicular epithelium. Surrounding the lumen, the oophoral cumulus was detected (Fig. 5 and 6). No visible oocytes were present in the tertiary follicles.
In the ovaries originating from the 15 month-old animal, atretic post-ovulation follicles containing corpora lutea were present (Fig. 7 and 8). The average diameter of the tertiary follicle was about 420 $\mu \mathrm{m}$, but most of them visualised on the slides were ellipsoidal. Both longitudinal and transversal measurements were taken to obtain the specified average diameter (Fig. 7). 
Histological characteristics of folliculogenesis in Murrah water buffaloes during the early ....

The corpora lutea consisted of luteotrophs with central nuclei and cytoplasmic lipid droplets. Small luteal cells with bundle shape and eccentric nuclei were also visualised (Fig. 8).

\section{DISCUSSION}

The histological examination carried out provided significant information on the nature of folliculogenesis in water buffalo heifers. Histological findings demonstrated different stages of follicular development and follicular maturation in the 11-month-old heifer. Additionally, the absence of active or regressing corpora lutea is suggestive of insufficient primary cycles occurring during the earlier stages of puberty, and consequently in the postpubertal period.

In many specimens, the observed follicles lacked a visible oocyte. This provides

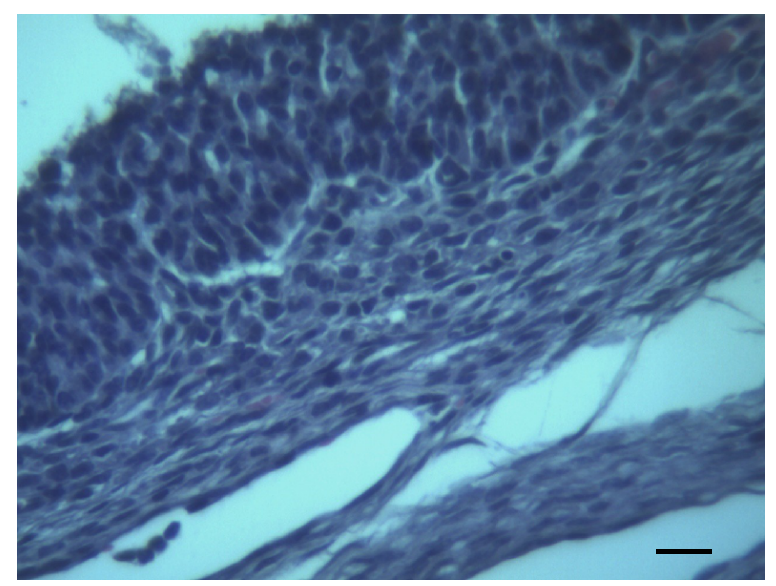

Fig. 3. Ovary from a water buffalo heifer - 11 months of age: secondary follicle, theca granulosa and connective tissue external layer. Scale bar: $17.30 \mu \mathrm{m}$.

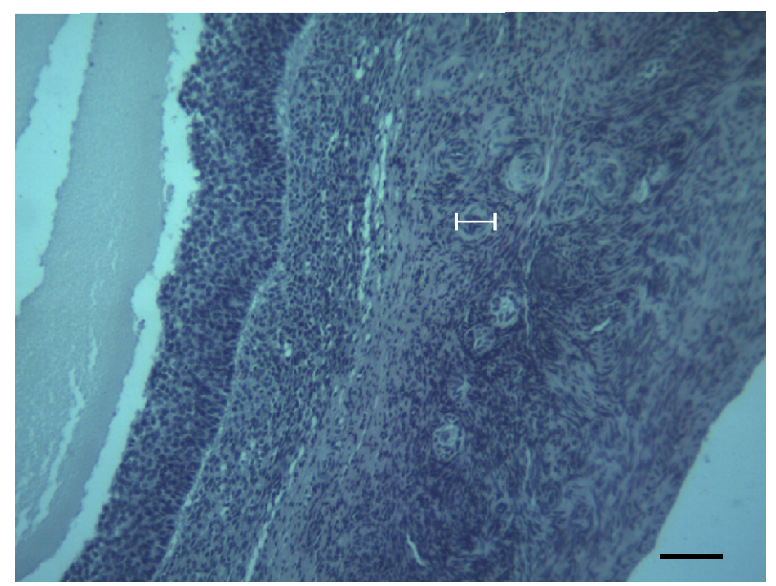

Fig. 4. Ovary from a water buffalo heifer - 14 months of age: ovarian cortex with tertiary follicle (length $36.67 \mu \mathrm{m})$, a few primary follicles in the periphery under the tunica albuginea. Scale bar: $66.67 \mu \mathrm{m}$. 


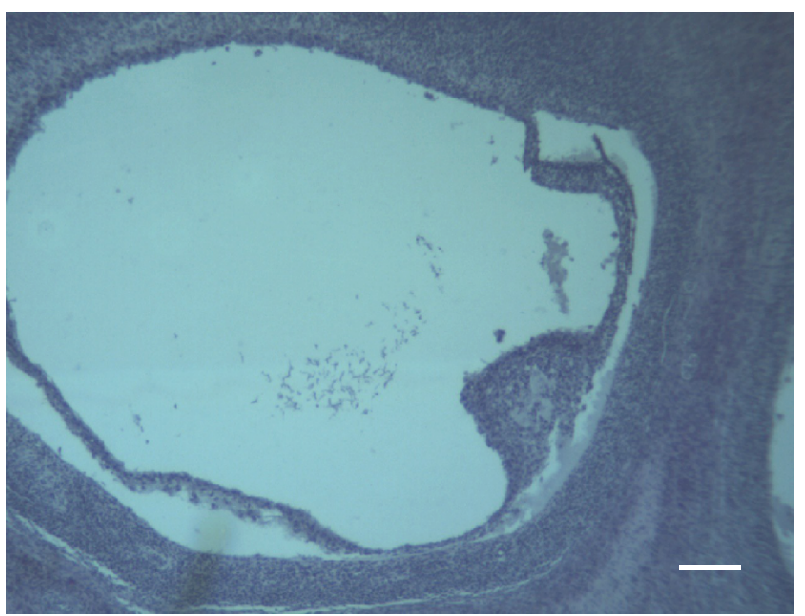

Fig. 5. Ovary from a water buffalo heifer - 14 months of age: tertiary follicle with oophoral cumulus. Scale bar: $66.67 \mu \mathrm{m}$.

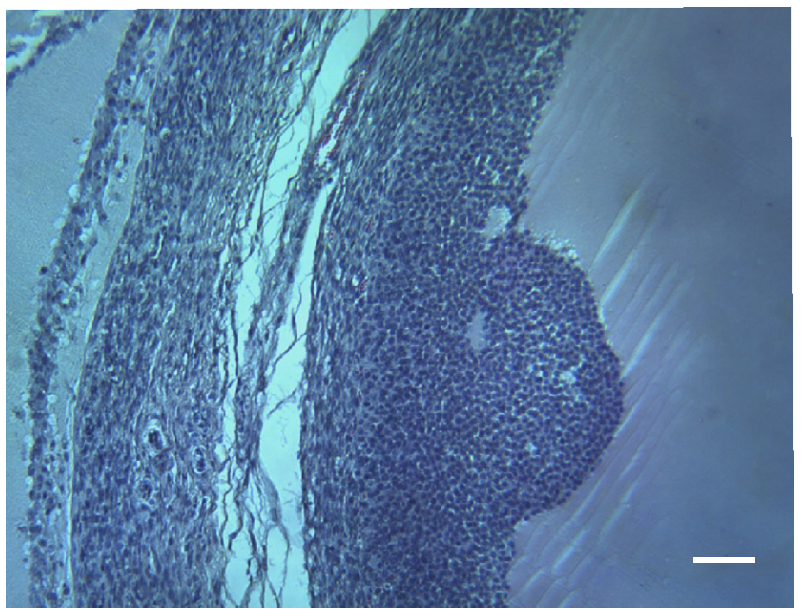

Fig. 6. Ovary from a water buffalo heifer -15 months of age: tertiary follicle with oophoral cumulus and absent oocyte. Scale bar: $66.67 \mu \mathrm{m}$.

support to the hypothesis that insufficiency of the cycle is present on an ovarian level. This insufficiency appears to last for a few cycles before and after puberty, or perhaps during the entire parapubertal period. The rest of the characteristics of follicular morphology are consistent with those observed in sexually mature animals. It must be stressed that the size of the examined atretic follicles was about $500 \mu \mathrm{m}$ which is significantly smaller compared to the size of the bovine atretic follicles $\leq 5 \mathrm{~mm}$ as described by Rodgers \& Irving-Rodgers (2010).

The presence of active corpora lutea on the histological sections of some of the older heifers suggests that there was endocrine induced control of luteal tissue re- 


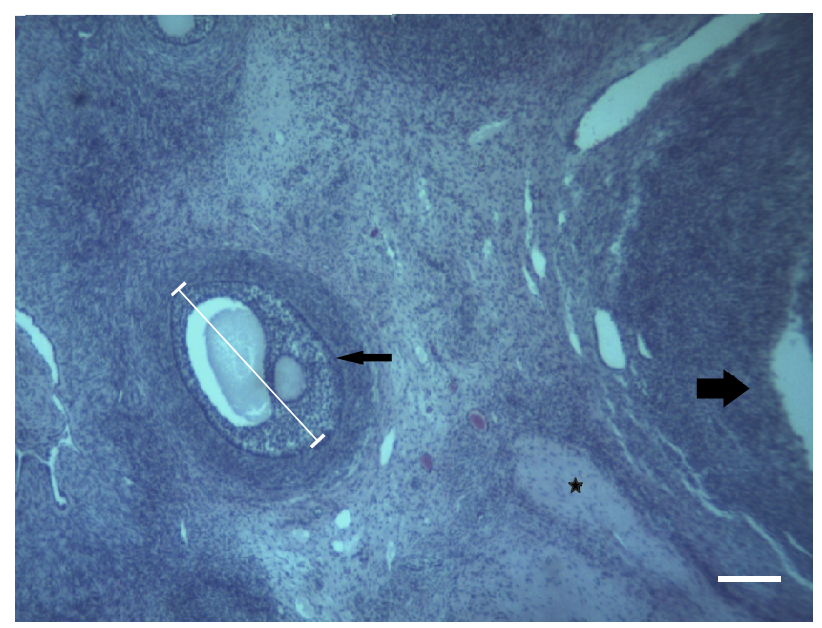

Fig. 7. Ovary from a water buffalo heifer - 15 months of age: atretic follicle, $500.47 \mu \mathrm{m}$ (narrow arrow), tertiary follicle (thick arrow) and luteal tissue (star). Scale bar: $153.14 \mu \mathrm{m}$.

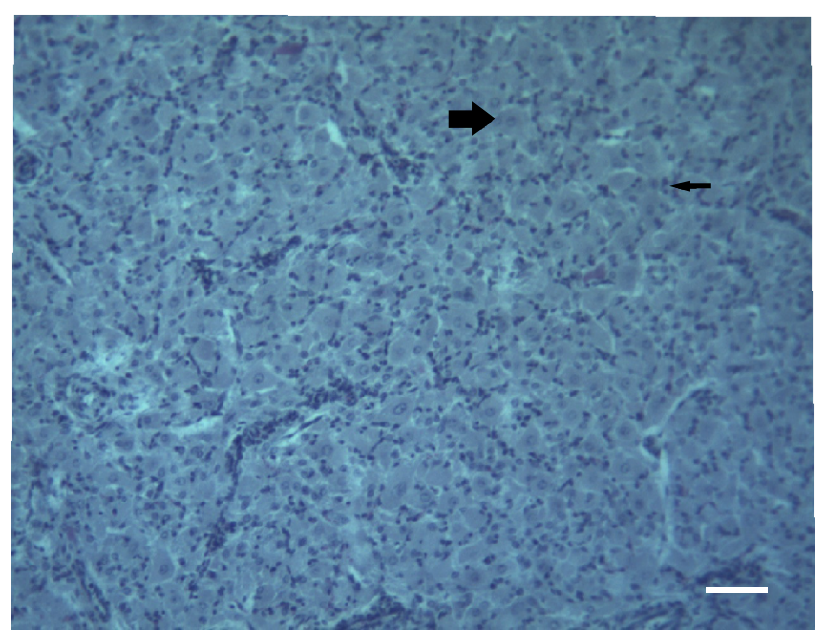

Fig. 8. Ovary from a water buffalo heifer - 15 months of age: corpus luteum. Luteotrophs with central nuclei and cytoplasmic lipid droplets (thick arrow), and small luteotrophs with bundle shaped nuclei (thin arrow). Scale bar: $66.67 \mu \mathrm{m}$.

quired for successful cycling in these animals. Further study of the hormone profiles of water buffalo heifers would clarify the endocrine component of the cycle in the postpubertal animals with follicles without oocytes.
The presented characteristics of the ovarian structures are comparable with available results (Taneja et al., 1996; Baithalua et al., 2013). The similarity is restricted to the type of the present structures but not to the histological characte- 
ristics. Data similar to ours are presented in the work of Baithalua et al. (2013) which was focused on CL cell characteristics, but not on general histology and follicular dynamics.

The presented structures in our results support the thesis for small tertiary follicle atresia previously stated by Fassi Fihri et al. (2004) and Rodgers \& Irving-Rodgers (2010).

Our findings are also similar with the average dimensions for the examined structures presented by Eurell \& Frappier (2006) for the secondary follicle -120 $\mu \mathrm{m}$. The visual characteristics of the follicles also match the description of the cited authors.

\section{CONCLUSIONS}

Histology is the definitive method for examination of ovarian activity in water buffalo. In some of the ovulating follicles the oocyte is absent during early puberty in water buffalo heifers. The presence of corpora lutea confirms the endocrine maturity of the HPG endocrine axis in the 11- 14 months old heifers despite the absence of oocytes.

\section{REFERENCES}

Baithalua, R. K., S. K. Singha, Ch. Gupta, A. K. R., A. Saxenaa, Y. Kumara, R. Singh \& S. K. Agarwala. 2013. Cellular and functional characterization of buffalo $(\mathrm{Bu}$ balus bubalis) corpus luteum during the estrous cycle and pregnancy. Animal Reproduction Science, 140, 138-146.

Baruselli, P. S., R. G. Mucciolo, J. A. Visintinz, W. G. Viana \& R. P. Arruda, 1997. Theriogenology, 47, 1531-1547.

Borghese, A. 2005. Buffalo Production and Research. Food and Agriculture Organization. Rome, Italy, pp. 17-27, ftp:// ftp.fao.org/docrep/fao/010/ah847e/ah847e. pdf.

Borghese, A., M.T erzano, V. Barile, A. Catalano, A. Maltati. 1996. Onset of puberty in buffalo heifers in different feeding and management systems. In: Proceedings of the International Symposium on Buffalo Resources and Production Systems. Cairo, Egypt, pp. 41-46.

Campanile, G., R. Di Palo, B. Casparini, D. Occio \& M. J. Zicarelli, 2001. Effects of early management system and subsequent diet on growth and consumption in buffalo heifers. Livestock Production Science, 71, 183-191.

Eurell, J. A. \& B. Frappier, 2006. Textbook of Veterinary Histology, $6^{\text {th }}$ edn, Blackwell Publishing, USA.

Fassi Fihri, A., K. H. Hajji \& H. Lakhdissi, 2004. Histological exploration of follicular population of the Moroccan bovine (Oulmes-Zaers) breed. African Journal of Biotechnology, 3, 294-298.

Jainudeen, M. R. \& E. S. E. Hafez, 1993. Reproductive cycles. In: Reproduction in Farm Animals, $6^{\text {th }}$ edn, Lea and Fabiger, Philadelphia, pp. 315-329.

Kanchev L., N. Bankov \& L. Kostov, 1989. Biology and Biotechnology of Reproduction, BAS Publishing, Sofia (BG).

Peeva Ts., K. Vankov, M. Tsankova, O. Polihronov, A. Dragoev \& A. Danev, 1993. All for Buffalo. Agrocomplex Ltd, Sofia (BG).

Planski, V., S. Yotov, M. Karadaev, Y. Ilieva, K. Hristov \& D. Dimitrov, 2017a. Determination of puberty onset in Bulgarian Murrah buffalo heifers through blood progesterone analysis. International Journal of Current Microbiology and Applied Sciences, 6, 308-314.

Planski, V., S. Yotov, P. Parvanov, M. Karadaev, Y. Ilieva, K. Hristov \& D. Dimitrov, 2017b. Influence of melatonin treatment on puberty onset in buffalo heifers from bulgarian murrah breed. Tradition and Modernity in Veterinary Medicine, 2 , 56-60. 
Histological characteristics of folliculogenesis in Murrah water buffaloes during the early ....

Rodgers, R. J. \& H. F. Irving-Rodgers, 2010. Morphological classification of bovine ovarian follicles, Reproduction, 139, 309318.

Roy, A. K., M. Singh, P. Kumar \& B. S. Kumar, 2016. Effect of extended photoperiod during winter on growth and onset of puberty in Murrah buffalo heifers. Veterinary World, 9, 216-221.

Singh, J., S. P. S. Chuman, D. Dadarwal, M. Hamparkhe, G. S. Whaliwal \& A. K. Jain, 2010. Estimation of blood plasma metabolites following melatonin implants treatment for initiation of ovarian cyclicty in true anestrus buffalo heifers. Indian Journal of Animal Sciences, 80, 229-231.

Slavkova, S., N. Markov, S. Stoycheva, 2017. Reproductive characteristics in reproduction of Bulgarian black and white cattle in the region of Pleven depending on the level of productivity. Journal of Mountain Agriculture on the Balkans, 20, 72-79.

Suthar, V. S. \& A. J. Dhami, 2010. Estrus detection methods in buffalo. Veterinary World, 3, 94-96.
Taneja, M. A. Ali \& G. Singh, 1996. Ovarian follicular dynamics in water buffalo. Theriogenology, 46, 121-130.

Terzano, G. M., A. Galasso, V. L. Barile, C. Pacelli, N. Mutemurro \& A. Borghese, 1997. Effect of feeding system and puberty on blood metabolites trends in buffalo heifers. In: Proceedings of the Fifth World Buffalo Congress, Caseita, Italy, pp. 951956.

Paper received 07.02.2018; accepted for publication 16.03.2018

\section{Correspondence:}

Georgi Stoychev Popov,

Faculty of Veterinary Medicine, University of Forestry,

Sofia, Bulgaria 1756 phone 0883488898 , e-mail: georgistpopov@yahoo.com 